\title{
Survival motor neuron SMN1 and SMN2 gene promoters: identical sequences and differential expression in neurons and non-neuronal cells
}

\author{
Bernadett Boda $^{1}$, Christophe Mas ${ }^{1}$, Catherine Giudicelli ${ }^{2}$, Virginie Nepote ${ }^{1}$, \\ Fabien Guimiot ${ }^{1}$, Béatrice Levacher ${ }^{1}$, Agnes Zvara ${ }^{1}$, Miklos Santha ${ }^{1}$, Isabelle LeGall ${ }^{2}$ and \\ Michel Simonneau*,1
}

\author{
${ }^{1}$ Neurogénétique/INSERM E9935, Hôpital Robert Debré, 48 Boulevard Sérurier, Paris, France; ${ }^{2}$ Fondation Jean Dausset/ \\ CEPH, 27 rue Juliette Dodu, Paris, France
}

Spinal muscular atrophy (SMA) is a recessive disorder involving the loss of motor neurons from the spinal cord. Homozygous absence of the survival of motor neuron 1 gene (SMN1) is the main cause of SMA, but disease severity depends primarily on the number of SMN2 gene copies. SMN protein levels are high in normal spinal cord and much lower in the spinal cord of SMA patients, suggesting neuron-specific regulation for this ubiquitously expressed gene. We isolated genomic DNA from individuals with SMN1 or SMN2 deletions and sequenced $4.6 \mathrm{~kb}$ of the $5^{\prime}$ upstream regions of the these. We found that these upstream regions, one of which is telomeric and the other centromeric, were identical. We investigated the early regulation of $S M N$ expression by transiently transfecting mouse embryonic spinal cord and fibroblast primary cultures with three transgenes containing 1.8, 3.2 and 4.6, respectively, of the SMN promoter driving $\beta$-galactosidase gene expression. The $4.6 \mathrm{~kb}$ construct gave reporter gene expression levels five times higher in neurons than in fibroblasts, due to the combined effects of a general enhancer and a non-neuronal cell silencer. The differential expression observed in neurons and fibroblasts suggests that the $S M N$ genes play a neuron-specific role during development. An understanding of the mechanisms regulating $S M N$ promoter activity may provide new avenues for the treatment of SMA.

European Journal of Human Genetics (2004) 12, 729-737. doi:10.1038/sj.ejhg.5201217

Published online 26 May 2004

Keywords: SMN; promoter; neuron

Introduction

Spinal muscular atrophy (SMA), which involves motor neuron loss and progressive paralysis, is one of the most common autosomal recessive disorders with a carrier frequency of 1 in 50. Three types (SMA I-III) have been described on the basis of onset and severity. Type I

*Correspondence: Prof M Simonneau, Neurogénétique/INSERM E 9935, Hôpital Robert Debré, Boulevard Sérurier, 75019 Paris, France. Tel: + 331 400319 23; Fax: + 331400319 03; E-mail: simoneau@infobiogen.fr Received 25 November 2003; revised 26 February 2004; accepted 27 February 2004
(Werdnig-Hoffmann) is the most severe form. ${ }^{1}$ The gene responsible for SMA maps to a region of inverted duplication on 5q11.2-q13.3 and is called survival of motor neuron $(S M N){ }^{2}$ Homozygous absence of the telomeric copy, SMN1, is the main cause of SMA. The centromeric copy, SMN2 differs in the regulation of exon splicing, resulting in exon skipping. ${ }^{3}$ The short isoform of the SMN protein, which is less stable than the full-length SMN protein, cannot compensate for the loss of the SMN1 gene in SMA patients. ${ }^{3}$ The severity of the disease is correlated with the amount of full-length SMN protein, which depends on the number of SMN2 gene copies. ${ }^{4,5} \mathrm{SMN}$ 
protein was first identified as part of a multiprotein complex that appears to play a critical role in spliceosomal snRNP assembly in the cytoplasm and is required for premRNA splicing in the nucleus. ${ }^{6-8}$ However, it is unclear why deficiency in $S M N$, a ubiquitously expressed gene, mostly affects neurons. SMN protein levels are high in normal spinal cord and much lower in the spinal cord of SMA patients. ${ }^{4,9,10}$ The level of SMN expression depends on synaptic activation. ${ }^{11}$ Furthermore, SMN appears to accumulate in axonal growth cones and dendrites. ${ }^{12,13}$ The function of SMN in motor axon development has been well conserved during evolution, as shown in zebrafish ${ }^{14}$ and in mice. ${ }^{15}$ Thus, there seems to be neuron-specific regulator elements in the SMN promoters. Previous studies of a $1.9 \mathrm{~kb}$ region upstream from the transcriptional start site of SMN1 and SMN2 found no difference in activity between the two promoters. ${ }^{16,17}$ We isolated genomic DNA from patients with deletions in SMN1 or SMN2, and sequenced $4.6 \mathrm{~kb}$ of the $5^{\prime}$ upstream region of the SMN1 and SMN2 genes; the sequences obtained were identical. We investigated the early regulation of $S M N$ expression by transiently transfecting mouse embryonic spinal cord and fibroblast primary cultures with three constructs containing 1.8, 3.2 and $4.6 \mathrm{~kb}$, respectively, of the SMN promoter driving $\beta$ galactosidase gene expression. The $4.6 \mathrm{~kb}$ construct gave levels of expression five times higher in neurons than in fibroblasts. This differential expression resulted from the effects of a combination of a general enhancer and a nonneuronal cell silencer. Our findings suggest that SMN protein may fulfil specific neuronal functions during development.

\section{Materials and methods \\ DNA sequencing and sequence analysis}

The upstream region of the SMN gene was analyzed for three patients (from Hôpital Robert Debré and Hôpital des Enfants Malades, Paris) diagnosed with SMA type I according to the criteria of the International SMA Consortium, and two healthy individuals with no SMN2 gene. DNA was isolated from peripheral venous blood by standard procedures. The number of centromeric (SMN2, C) and telomeric (SMN1, T) copies of the gene in the patients was determined by competitive PCR of exon $7^{18}$ : the three SMA patients had 2C/OT and two normal individuals had 0C/2T genotypes. We amplified the $4.6 \mathrm{~kb}$ upstream from $S M N$ exon 1 by polymerase chain reaction (PCR) (Expand ${ }^{\mathrm{TM}}$ Long Template PCR System, Boehringer), using genomic DNA as the template. The PCR products were subjected to electrophoresis and purified from the gel with the Nucleo Trap DNA purification kit (Clontech) and were inserted into the pSTBlue-1 vector (Novagen), according to the manufacturer's instructions. The $4.6 \mathrm{~kb}$ upstream region used for transgene construction was also sequenced after purification, as described below. Subcloned DNA was sequenced with the BigDye Terminator Cycle Sequencing Ready Reaction kit with AmpliTaq DNA Polymerase, FS (Perkin-Elmer, Applied Biosystems Division), on an automated ABI PRISM 377 XL DNA Sequencer (Perkin-Elmer, Applied Biosystems Division), following the manufacturer's instructions. If we were unable to obtain a clear sequence with a particular primer (GT-rich or G-rich region, secondary structure, certain sequence contexts or motifs), sequencing reactions were performed with the dGTP BigDye Terminator Ready Reaction kit (Perkin-Elmer, Applied Biosystems Division).

Sequence alignments were analyzed with the Lfasta and Lalign programs (FASTA package). Transcription factor sites were analyzed with the Transcription Element Search System (TESS; TRANSFAC 4.0). ${ }^{19}$ Repressor element-1 silencing transcription/neuron-restrictive silencer factor (REST/NRSF) binding sites were investigated using MatInspector $^{20}$ to query the TRANSFAC 6.0 database. ${ }^{21}$

Clone isolation and generation of reporter constructs We used the SalI-EcoRI insert of P815E1, containing $5.3 \mathrm{~kb}$ of the $5^{\prime}$ region with exon 1 and part of intron 1 of the SMN1 gene, from a FIXII lambda phage library constructed from YAC clones (P815E1). A 5079-base SalI-XhoI fragment was isolated from P815E1. This fragment was inserted into the XhoI site in the polylinker of the pNASS $\beta$ vector (Clontech). The $3.2 \mathrm{~kb}$ promoter fragment construct was obtained from the $4.6 \mathrm{~kb}$ promoter fragment construct by deleting a 1387-base KpnI-EcoRI fragment. The $1.8 \mathrm{~kb}$ promoter fragment was obtained by PCR, with the addition of an EcoRI site, and was inserted into the pNASS $\beta$ vector. The CMV-luciferase reporter construct was made from a pGL2-based vector (Promega) with a CMV insert (MluIHindIII fragment from pcDNA3; Invitrogen), inserted upstream from the luciferase gene, this fragment being removed and then inserted between the same sites of the polylinker (gift from Drs N Oudhiri and P Lehn).

\section{Cell cultures}

For the preparation of mouse fibroblast primary cultures, E14 mouse embryos were dissected, with the head removed and the internal organs scooped out. The carcasses were minced and placed in a bottle containing $0.05 \%$ trypsin/ EDTA in $\mathrm{Ca}^{2+} \mathrm{Mg}^{2+}$-free phosphate-buffered saline (PBS) supplemented with $0.1 \%$ glucose. The bottle was shaken at room temperature for $40 \mathrm{~min}$. The supernatant was centrifuged $(1500 \mathrm{~g}, 5 \mathrm{~min})$. The pellet was resuspended by repeated trituration through a fire-polished Pasteurpipette and plated in culture dishes. Fibroblasts were maintained in Dulbecco's modified Eagle's medium (DMEM) supplemented with 10\% fetal calf serum (FCS), penicillin $(50 \mathrm{U} / \mathrm{ml})$ and streptomycin $(50 \mathrm{mg} / \mathrm{ml})$. The cells were passaged before transfection.

For the preparation of mouse spinal cord primary culture, mouse spinal cords were taken from E12-E13 
embryos, dissected and cultured as described by Ransom et $a .^{22}$ The cords were minced and incubated with $0.1 \%$ trypsin in $\mathrm{Ca}^{2+} \mathrm{Mg}^{2+}$-free PBS for $15 \mathrm{~min}$, at $37^{\circ} \mathrm{C}$. Cells were centrifuged $(1500 \mathrm{~g}, 5 \mathrm{~min})$, resuspended and plated on tissue culture dishes or coverslips treated with rat-tail collagen (Jacques-Boy). The growth medium was DMEM supplemented with 10\% Serum Supreme (BioWhittaker), penicillin $(50 \mathrm{U} / \mathrm{ml})$ and streptomycin $(50 \mathrm{mg} / \mathrm{ml})$. The medium was changed every other day.

\section{Transient expression experiments}

The SMN constructs (plasmids) were used to transfect primary cultured neurons $1-7$ days after plating or primary mouse fibroblast cultures, using LipofectAmine (Life Technologies). Three to six independent transfections were carried out for each construct and cell type. Plasmid DNA was added to the cells in $500 \mu \mathrm{l}$ base medium without supplementation or in Optimem medium (Life Technologies) for neurons, with $20 \mu \mathrm{l}$ LipofectAmine, and the mixture was incubated for $20-30 \mathrm{~min}$ and then added to a $60 \mathrm{~mm}$ dish. After $4 \mathrm{~h}$, the culture was fed with fresh medium. The plasmids used for transfection were purified with the cesium chloride method, as described by Sambrook et al. ${ }^{23}$ Results were standardized by cotransfection with the $S M N$-reporter lac $Z$ construct $(7 \mu \mathrm{g})$ and the CMVluciferase reporter gene $(1 \mu \mathrm{g})$. pCH110 (Pharmacia) was used as the positive control.

$\beta$-Galactosidase activity was quantified with a luminescent $\beta$-galactosidase detection kit (Clontech), as described in the product protocol. Briefly, cell lysates were prepared from transfected cells in $60 \mathrm{~mm}$ culture dishes by repeated freeze/thaw cycles. For $\beta$-galactosidase detection, $10 \mu \mathrm{l}$ of each lysate was then incubated with $200 \mu \mathrm{l}$ reaction buffer (containing Galacton-Star substrate and Sapphire enhancer) for $1 \mathrm{~h}$. $\beta$-Galactosidase activity was then measured with a LUMAT LB 9501 luminometer (Berthold). A further $20 \mu$ l of lysate from the same culture dish was immediately transferred to a luminometer tube and the luciferase activity was determined by injecting $80 \mu \mathrm{M}$ luciferin and $1.2 \mathrm{mM}$ ATP in $100 \mu \mathrm{l}$ of reaction buffer.

\section{Immunofluorescence microscopy}

Cells grown on coverslips were washed twice with PBS for $5 \mathrm{~min}$ each and fixed in $100 \%$ methanol at $-20^{\circ} \mathrm{C}$ for $10 \mathrm{~min}$. The cells were washed twice with PBS and then incubated with 3\% bovine serum albumin, 0.1\% Tween-20 in PBS for $30 \mathrm{~min}$. The primary antibodies used were: mouse monoclonal anti-neurofilament $160 \mathrm{kDa}$ (IgG1) (Novocastra), rabbit polyclonal anti- $\beta$-galactosidase $\left(5^{\prime}-\right.$ $3^{\prime}$ ) and monoclonal anti-PSA N-CAM (provided by Dr Rougon). The primary antibodies were added to the cells and the mixture was incubated for $2 \mathrm{~h}$. Anti-neurofilament antibody was diluted $1: 25$, anti- $\beta$-galactosidase $1: 500$ and anti-PSA N-CAM 1:100. The cells were washed three times with $0.1 \%$ Tween-20 in PBS and incubated with the secondary antibodies: goat anti-mouse IgG1 conjugated with fluorescein isothiocyanate (FITC) (dilution 1:100; Sigma), goat anti-rabbit IgG conjugated with cyanin (Cy3) (dilution 1:100; Jackson ImmunoResearch) or FITCconjugated goat anti-rabbit -IgG (dilution 1:100; Jackson ImmunoResearch) and goat anti-mouse IgM conjugated with phycoerythrin (PE) (dilution 1:80; Jackson ImmunoResearch) for $1 \mathrm{~h}$. The labeled cells were examined with a Leica DMRB light microscope and by confocal laser scanning microscopy (CSLM, Leica). In confocal microscopy, cells were optically sectioned in the $x-y$ planes every $0.5 \mu \mathrm{m}$ and the images generated were photographed.

\section{Fluorescence-activated cell analysis and sorting (FACS analysis)}

Spinal cords from E12-E13 embryos were microdissected and cultured as described above. They were stained with fluorogenic substrate as described by Leconte et al. ${ }^{24}$ The day after plating, cells were transfected with the $4.6 \mathrm{~kb}$ SMN promoter construct. They were incubated for $48 \mathrm{~h}$, then collected and prepared for immunohistochemistry by incubation with anti-PSA N-CAM antibody and fluorescein di-beta-galactopyranoside (FDG). Cells were incubated with FDG, in 10\% FCS-supplemented culture medium mixed with an equal volume of prewarmed $\left(37^{\circ} \mathrm{C}\right) 2 \mathrm{~mm}$ FDG for $1 \mathrm{~min}$, as described by Nolan et al. ${ }^{25}$ FDG loading was stopped by placing the cell samples on ice. Then cells were analyzed with an Elite ESP Beckman-Coulter flow cytometer. We analyzed 10000 cells per experiment and carried out five independent experiments.

\section{Statistical analysis}

Statistical analysis was carried out by means of one-way ANOVA and unpaired two-tailed $t$-tests. Significance was defined as $P<0.05$.

\section{Accession numbers}

GenBank accession numbers: PAC 125D9: U80017, PAC RP1-215P15: AC004999, SMN1 promoter: AF189367, SMN2 promoter: AF187725.

\section{Results \\ Identity of the $4.6 \mathrm{~kb} 5^{\prime}$ regions of the $S M N 1$ and $S M N 2$ genes \\ Although the cDNAs for the two SMN genes differ by only one translationally silent nucleotides, only the SMN1 gene has been implicated in causing SMA. SMA type I patients seem to have only about one-hundredth the SMN protein present in normal individuals. ${ }^{4}$ However, as this level of SMN protein likely reflects expression of SMN2 in SMA patients, this would imply that SMN2 is expressed at much lower level than SMN1, raising the question of possible differences in the promoters of the SMN1 and SMN2 genes. The SMN1 and SMN2 flanking regions upstream from the}


Table 1 Nucleotide comparison between the $4.6 \mathrm{~kb}$ upstream sequences of PAC 125D9, 215P15, three SMN2 and three SMN1 genes

\begin{tabular}{|c|c|c|c|c|}
\hline \multirow[b]{2}{*}{ Position } & \multicolumn{2}{|c|}{ SMN2 } & \multicolumn{2}{|c|}{ SMN1 } \\
\hline & $\begin{array}{l}\text { PAC 215P15 } \\
\text { Centromeric }\end{array}$ & $\begin{array}{c}\text { SMA I } \\
2 \mathrm{C} / 0 T(n=3) \\
\text { Centromeric }\end{array}$ & $\begin{array}{c}\text { Unaffected } \\
0 \mathrm{C} / 2 T(n=2) ; \text { and P815E1 } \\
\text { Telomeric }\end{array}$ & $\begin{array}{l}\text { PAC } 125 D 9 \\
\text { Telomeric }\end{array}$ \\
\hline-4379 & A & - & - & - \\
\hline-4323 & A & A & A & $G$ \\
\hline-4052 & A & A & A & $\mathrm{T}$ \\
\hline-3503 & G & G & G & - \\
\hline-2781 & G & G & G & C \\
\hline-2188 & A & A & A & C \\
\hline-2156 & $\mathrm{~T}$ & $\mathrm{~T}$ & $\mathrm{~T}$ & C \\
\hline-2132 & T & $\mathrm{T}$ & $\mathrm{T}$ & C \\
\hline-1911 & G & G & G & C \\
\hline-1759 & - & - & - & A \\
\hline-1729 & $\mathrm{~T}$ & $\mathrm{~T}$ & T & A \\
\hline-1574 & G & G & G & C \\
\hline-1563 & G & G & G & C \\
\hline-1291 & A & A & A & G \\
\hline-1029 & G & G & G & A \\
\hline-908 & - & - & - & AGG \\
\hline-460 & - & - & - & GCC \\
\hline-222 & $\mathrm{~T}$ & $\mathrm{~T}$ & $\mathrm{~T}$ & G \\
\hline
\end{tabular}

The sequences from the six individuals analyzed are strictly identical to PAC 215P15, except for an A found at position -4379 that we did not considered to be a genuine difference. Nucleotide position was calculated from the transcription initiation site, as described by Echaniz-Laguna et al. ${ }^{17}$

transcriptional start site are limited by the $3^{\prime}$ untranslated region of the contiguous SERF1A, gene. ${ }^{26}$ Based on these physical map data, we decided to sequence $4.6 \mathrm{~kb}$ upstream from the transcriptional initiation site of the two SMN genes in the genomic DNA of six individuals: (i) three SMA type I patients lacking SMN1 but each with two SMN2 genes, to analyze SMN2 promoter; (ii) three unaffected individuals lacking SMN2 but with two SMN1 genes, for analysis of the SMN1 promoter, together with a telomeric clone derived from an unaffected individual with both SMN1 and SMN2 (P815E1, DNA provided by Judith Melki). The SMA type I patients lacking SMN1 and two of the unaffected individuals lacking SMN2 have been described elsewhere. ${ }^{27}$ These six sequences were compared with those of PACs 125D9 and 215P15. PAC 125D9 corresponds to the SMN1 gene and has already been sequenced. The other PAC, 212P15, contains the centromeric SMN2 gene, as shown by the presence of the silent nucleotide change in exons 7. In PAC 125D9 (SMN1), 18 nucleotide differences were found in addition to differences in the number of CA repeats. In contrast, for the whole of each of the $4.6 \mathrm{~kb}$ upstream region analyzed (three SMN1; three SMN2), we found no differences from the reported sequence of PAC 215P15, except in the number of CA repeats corresponding to the polymorphic markers, C272 or D5S1556 (Table 1). The number of CA repeats was variable and not related to the number of SMN1 or SMN2 copies. Interestingly, no single-nucleotide polymorphisms were present in these $4.6 \mathrm{~kb}$ sequences. Furthermore, SMN promoter sequences from the six individuals were $100 \%$ identical to the human genome reference sequence (NCBI build 34, July 2003), as shown by analysis with the UCSC genome browser. ${ }^{28}$ We then analyzed putative regulatory elements in the promoter regions of the SMN genes. TESS software identified a large variety of possible binding sites for transcription factors. We identified $12 \mathrm{Sp} 1$, eight AP1, three AP-2, six HNF-3, 24 Zeste and four RXR-beta sites. REST/NRSF binds a DNA element, RE-1, in the regulatory regions of many neuronal genes. ${ }^{29-32}$ No RE-1 elements were identified either by MatInspector (TRANSFAC 6.0) or by visual inspection.

Enhanced expression in neurons with the $4.6 \mathrm{~kb} S M N$ promoter region is linked to the effects of a combination of a general enhancer and a non-neuronal silencer

Kanai and Hirokawa ${ }^{33}$ reported the transfection of mouse spinal cord primary cultures with expression vectors for MAP2 and tau proteins, using Lipofectamine. We used a similar approach to study the expression of $S M N-l a c Z$ fusion constructs in mouse neuroblasts. Cells were dissociated on embryonic day 13 , transfected after 1-7 days of culture, and stained with X-Gal 2 days after transfection. We successfully transfected postmitotic neurons with $S M N$ transgenes. This was demonstrated by double immunostaining of transfected cells with an antibody directed against the reporter gene and another directed against neurofilament middle $(160 \mathrm{kDa})$ (NFM) protein, which is 
known to be specific for postmitotic neurons ${ }^{34,35}$ (Figure 2a). Interestingly, the SMN- $\beta$-galactosidase fusion protein was detected only in the cytoplasm of neurons from primary cultures of mouse embryonic spinal cord. This cytoplasmic location indicates that the first SMN exon is insufficient to target this protein to the nucleus.

We used this primary culture model for further analysis of three transgenes containing $1.8,3.2$ and $4.6 \mathrm{~kb} S M N$ promoter fragments driving $\beta$-galactosidase gene expression (Figure 1). SMN promoter activity was quantified for primary cultures transfected after 1 day of culture, for all three $S M N$ constructs (Figure $2 \mathrm{~b}$ ). The $\mathrm{pCH} 110$ vector was used as a positive control (SV40-lacZ). Results were standardized by cotransfection with a CMV-luciferase reporter gene. As the results obtained with pCH110 positive controls did not differ significantly between embryonic spinal cord and fibroblast cultures, we were able to compare the activity of the transgenes directly in the two types of primary culture for each $5^{\prime}$ sequence.

We found that the $1.8 \mathrm{~kb}$ construct was expressed four times more strongly in primary mouse spinal cord than in fibroblast cultures $(P<0.0005)$. The $3.2 \mathrm{~kb} S M N$ promoter gave significantly stronger $(P<0.005$ for fibroblast cultures and $P<0.05$ for spinal cord cultures) expression of the reporter gene compared to the $1.8 \mathrm{~kb}$ promoter in both types of primary cultures. However, the $3.2 \mathrm{~kb} S M N$ promoter gave higher levels of expression in neurons than in fibroblasts. The $4.6 \mathrm{~kb} S M N$ promoter behaved similarly to the $3.2 \mathrm{~kb} S M N$ promoter in neurons. In contrast, this construct gave levels of expression in fibroblasts lower than those achieved with the $3.2 \mathrm{~kb} S M N$ promoter by a factor of $2.5(P<0.05)$, resulting in a five-fold difference between these two types of primary cultures $(P<0.05)$. These results

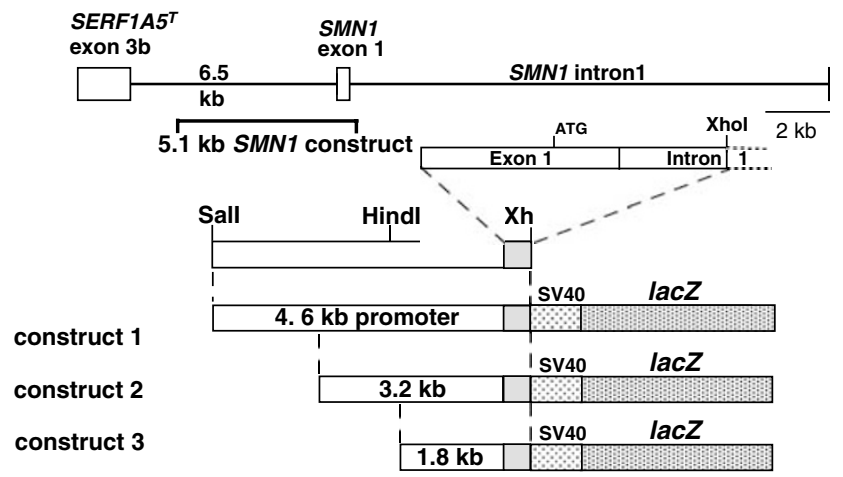

$\square$ SV 40: splice donor/splice accepto

$\square$ SMN1 exon1 and part of intron 1

Figure 1 Schematic representation of the SMA region and SMN1 constructs. SMN expression constructs. All constructs were generated using a pNASS $\beta$-lac $Z$ vector. The promoter-less plasmid was included to estimate the background activity of the plasmid.
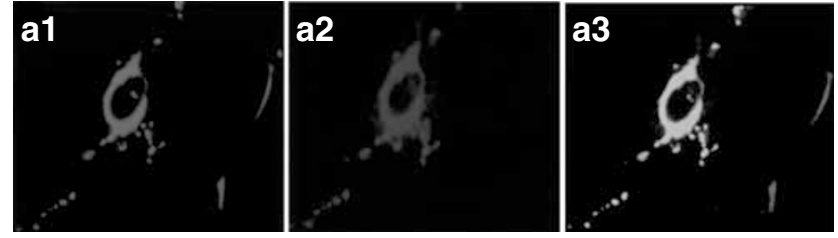

b

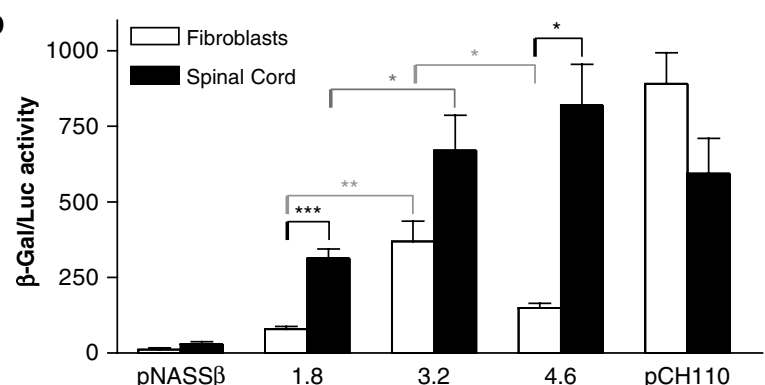

Figure 2 The $4.6 \mathrm{~kb}$ construct gave expression levels five times higher in spinal cord primary cultures than in fibroblast cultures. (a) Double immunostaining of a neuron from mouse embryo primary spinal cord culture after transfection with an SMN construct. Double immunostaining with monoclonal anti-neurofilament $160 \mathrm{kDa}$ (NFM) protein antibody (a1) and polyclonal anti- $\beta$-galactosidase antibody (a2) with the two images superimposed in (a3). Spinal cord cells were transfected with the $4.6 \mathrm{~kb}$ SMN construct after 1-7 days of culture and were maintained in culture for 6 days after transfection. Note that $\beta$-galactosidase was restricted to the cytoplasm of neurons, indicating that the first exon of SMN is insufficient to target this fusion protein to the nucleus. Scale bar: $20 \mu \mathrm{m}$. (b) Relative activities of the $1.8,3.2$ and $4.6 \mathrm{~kb}$ SMN promoter constructs, pCH110 (SV40-lacZ) construct and the promoter-less vector $(\mathrm{pNASS} \beta)$ in primary spinal cord and fibroblast cultures. All constructs were generated using a pNASS $\beta$-lacZ vector. The promoter-less plasmid was included to estimate the background activity of the plasmid. The histograms show the ratio of $\beta$-galactosidase activity for the constructs analyzed to the luciferase activity of the CMV-Luc construct. The results are means \pm SD of at least three independent experiments. The difference between the 1.8 and $3.2 \mathrm{~kb}$ (red bar; red ${ }^{* *}$ ) and between the 3.2 and $4.6 \mathrm{~kb}$ (red bar; red *) SMN promoter constructs are significant $(P<0.005$ and $P<0.05$, respectively) in primary fibroblast cultures. Also, the difference between the 1.8 and $3.2 \mathrm{~kb}$ (blue bar; blue *) SMN promoter constructs is significant $(P<0.05)$ in primary spinal cord cultures. No significant difference was found between the 3.2 and $4.6 \mathrm{~kb}$ constructs in primary spinal cord cultures. Significant differences $(P<0.0005$ and $P<0.05)$ were observed between primary spinal cord and fibroblast cultures for the $1.8 \mathrm{~kb}$ (black bar; black ***) and $4.6 \mathrm{~kb}$ (black bar; black *) SMN promoter constructs.

suggest that there is an enhancer element between 1.8 and $3.2 \mathrm{~kb}$ upstream from the transcriptional start site of the $S M N$ genes, which functions in both culture types, and a 
silencer between 3.2 and $4.6 \mathrm{~kb}$, which is active only in fibroblast cultures. The combined effect of these two elements results in strong expression in mouse embryonic spinal cord cultures.

Enhanced expression in neurons with the $4.6 \mathrm{~kb} S M N$ promoter region analyzed by fluorescent cell sorting To confirm the magnitude of the difference in expression between neurons and fibroblasts, we used a complementary approach combining reporter gene analysis and automatic cell sorting. We previously demonstrated that only embryonic motor neurons in E13-E14 spinal cord cultures produce the polysialylated cell adhesion protein PSA N-CAM. ${ }^{36}$ We used this pattern of expression for the selective sorting of motor neurons from spinal cord cultures transfected with the $4.6 \mathrm{~kb} S M N$ promoter construct, using an anti PSA N-CAM antibody (Figure 3a). We then assessed SMN promoter activity, using a fluorogenic substrate for beta-galactosidase ${ }^{25}$ (Figure $3 b-d$ ).

We compared the fluorescence intensities of neuron and fibroblast populations transfected with the same $4.6 \mathrm{~kb}$ $S M N$ promoter construct (Figure $3 \mathrm{~b}, \mathrm{c}$ ). SMN promoter activity was five times higher in PSA N-CAM neurons than in fibroblasts (Figure 3d, e).

\section{Discussion \\ Strict duplication of $S M N$ promoter sequences: implications for SMA disease}

Analysis of the sequences of six human genomic DNAs demonstrated that the $4.6 \mathrm{~kb}$ region upstream from the transcriptional start site was identical in the telomeric and centromeric copies of the $S M N$ gene. We identified no single-nucleotide polymorphisms in this $4.6 \mathrm{~kb}$ sequence. Our results extend those of Echaniz-Laguna et al, ${ }^{17}$ who found no differences in sequence between the $2 \mathrm{~kb}$ immediately upstream from the SMN1 and SMN2 genes, except for the number of CA repeats. The 19 base differences from the sequence of PAC 125D9 may be accounted for by errors in the sequencing of this reference clone.

The strict identity of the SMN1 and SMN2 sequences raises the question as to why two functional copies with an identical promoter region are present in humans, whereas only one $S M N$ gene copy is found in rodents. ${ }^{37,38}$ Previous studies have reported the duplication of human genes but the duplicated copies are generally nonfunctional pseudogenes, such as the steroid 21-hydroxylase gene, CYP21 $1^{39}$ and the polycystic kidney disease gene. ${ }^{40}$ However, SMN2 is not the only known example of a functional copy resulting from gene duplication, in humans. For example, the FKBP6 gene is present in duplicons flanking the $\sim 1.6 \mathrm{Mb}$ genomic region deleted in Williams-Beuren syndrome. ${ }^{41}$ These duplicated regions act as recombination hot spots, involved in genome instability and human diseases. ${ }^{42}$ As
SMN2 may have evolved at the same point in evolution as the other human gene copies, the absence of single-base mutations in the $4.6 \mathrm{~kb}$ upstream promoter region is striking. This lack of mutation may reflect a functional advantage of having two expressed SMN copies, which may be related to quantitative differences in motor neuronmuscle physiology between humans and rodents.

Greater neuronal expression with the $4.6 \mathrm{~kb}$ construct than with the $1.8 \mathrm{~kb}$ construct

In normal conditions, $S M N$ is known to be strongly expressed in neurons in both fetal and postnatal spinal cord, ${ }^{4,10}$ but the mechanism underlying this expression pattern has not been identified. In this study, we showed, by transfecting primary cell cultures, that three reporter constructs containing $1.8,3.2$ and $4.6 \mathrm{~kb}$ of the $S M N$ promoter were all expressed. We also demonstrated, by confocal microscopy, that the first exon of the SMN gene was not sufficient to direct expression of the lac $Z$ reporter gene in the nucleus (Figure 2a). Pellizzoni et $a l^{8}$ demonstrated that a mutant SMN protein lacking the first 27 amino acids (SMN $\Delta$ N27) was present in the nucleus but caused dramatic reorganization of snRNPs, gems and coiled bodies, resulting in a lack of pre-mRNA splicing stimulation. Zhang et al (2003) recently demonstrated that the exon-7 deletion mutant is confined to the nucleus. Thus, in vitro primary culture systems for neurons can be used to define the sequences responsible for SMN nuclear targeting.

The $4.6 \mathrm{~kb}$ sequence contains a large variety of potential binding sites for transcription factors, such as Sp1, Ap1, Zeste and RXR-beta, as expected for a gene promoter region. Remarkably, we found 24 putative Zeste sites. The Zeste protein is involved in transvection events in Drosophila $^{43}$ and Zeste sites have been identified in other promoters, such as that of the mouse PAX 8 gene. ${ }^{44}$ We also found consensus binding sites for AP2 and HNF-3, which may be involved in the differentiation and survival of neuronal cells. ${ }^{45,46}$

SMN promoter activity analysis in cell lines has generated conflicting results, ${ }^{16,47}$ suggesting that fine transcriptional regulation is not conserved in established cell lines. Our data, obtained in primary cultures, indicate the likely presence of a general enhancer and a non-neuronal cell silencer in the promoter sequence, as the $4.6 \mathrm{~kb}$ construct gave levels of reporter gene expression levels five times higher in neurons than in fibroblasts. Subsets of genes important for neuronal function are turned off in nonneuronal cells by the expression of REST/NSRF genes, the product of which binds to NSRE sequences. ${ }^{30-32}$ Interestingly, no repressor element-1 silencing transcription/ neuron-restrictive silencer factor (REST/NRSF) binding sequences were detected in the $4.6 \mathrm{~kb}$ sequence. Thus, a nonclassical silencing mechanism acting specifically in 

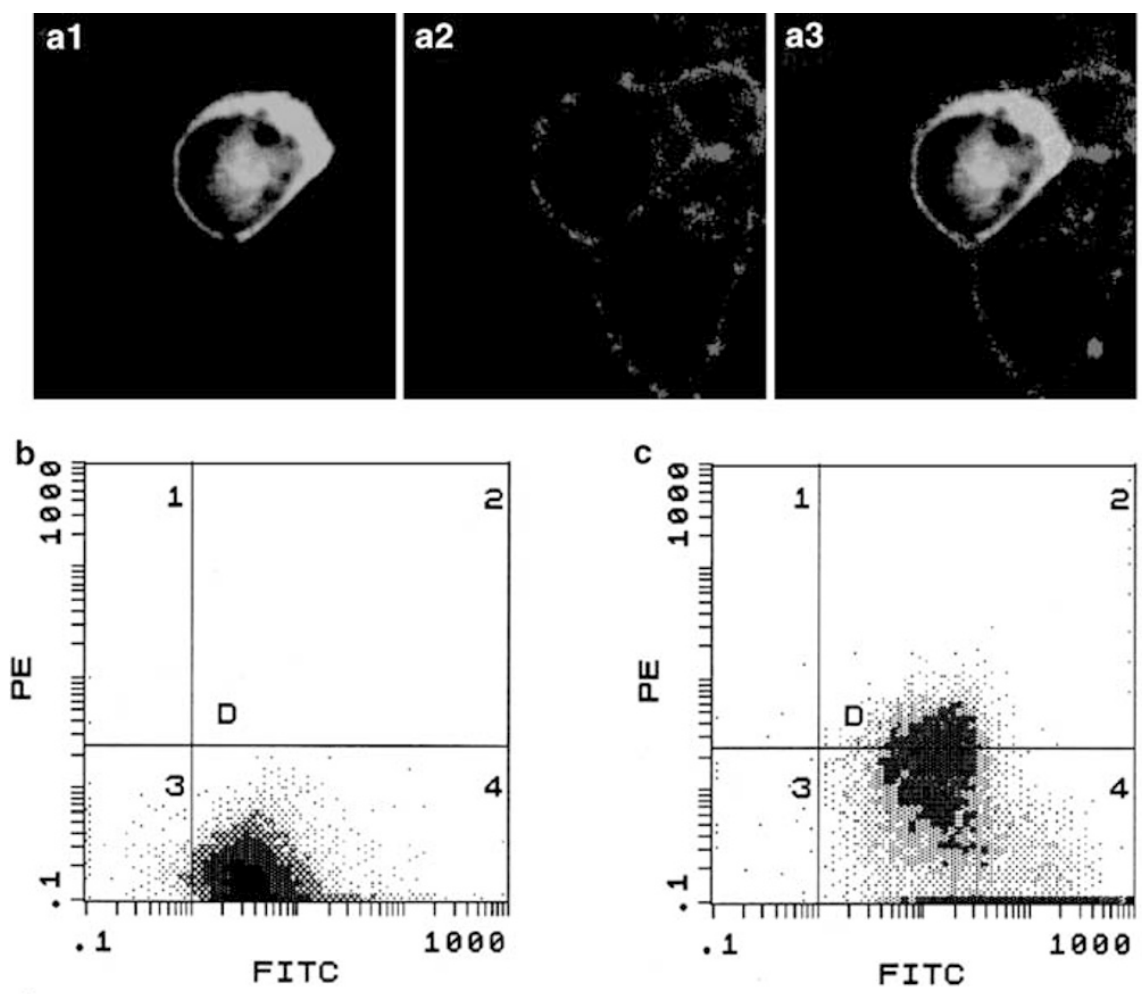

d

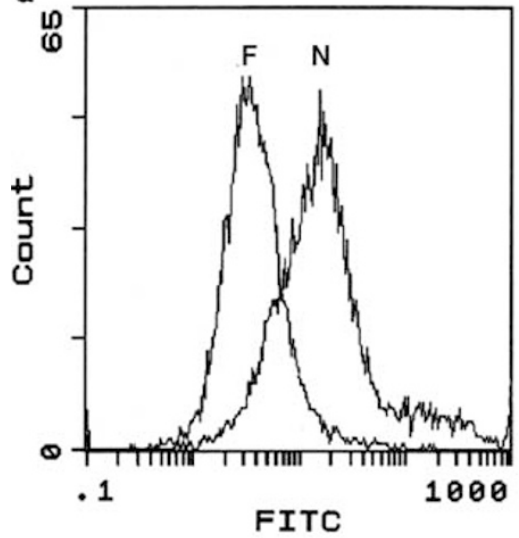

C

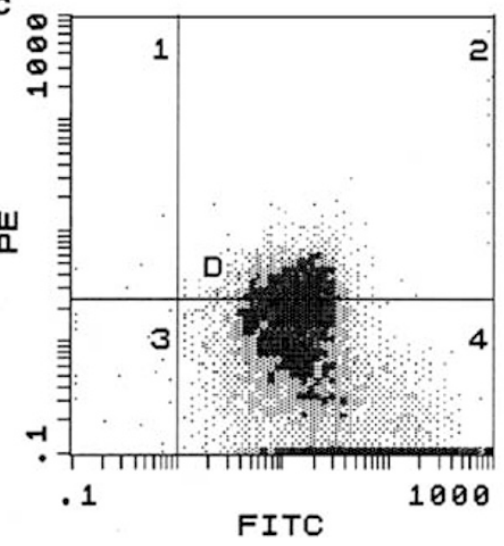

e

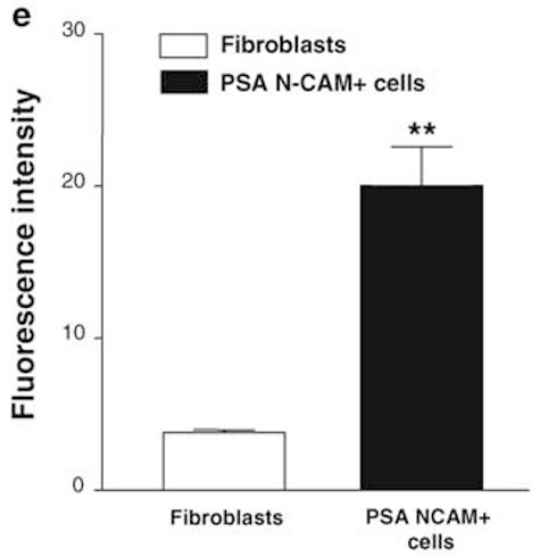

Figure 3 Greater activity of the $4.6 \mathrm{~kb}$ SMN promoter in neurons, as shown by FACS analysis. (a) Immunohistochemistry of primary spinal cord culture after transfection with the $4.6 \mathrm{~kb}$ SMN promoter construct. Cells grown on coverslips were washed twice with PBS for $5 \mathrm{~min}$ each and fixed in $100 \%$ methanol at $-20^{\circ} \mathrm{C}$ for $10 \mathrm{~min}$. Cells were washed twice and incubated for $30 \mathrm{~min}$ with $3 \%$ bovine serum albumin in PBS supplemented with $0.1 \%$ Tween-20. The primary antibodies, rabbit polyclonal anti- $\beta$-galactosidase and mouse monoclonal anti-PSA N-CAM antibodies, were added and the mixture was incubated for $2 \mathrm{~h}$. Anti- $\beta$-galactosidase antibody was diluted 1:500 (a1) and anti-PSA N-CAM antibody 1:100 (a2). The cells were washed three times with 0.1\% Tween-20 in PBS and incubated with the secondary antibodies - PE-conjugated goat anti-mouse IgM (dilution 1:80) and FITC-conjugated goat anti-rabbit IgG (dilution 1:100; Jackson ImmunoResearch) - for $1 \mathrm{~h}$. A merged confocal image is shown in (a3). (b, c) Representative flow cytometry analyses of fibroblast (b) and neuronal (c) cell populations are shown. (d) FITC intensity histograms for sorted transfected fibroblasts (F) and neurons (N). Cells were plated in $60 \mathrm{~mm}$ culture dishes, transfected with the $4.6 \mathrm{~kb}$ SMN promoter construct $24 \mathrm{~h}$ after plating and analyzed by FACS $48 \mathrm{~h}$ after transfection. Cells were immunostained with the anti-PSA N-CAM antibody, a specific marker of the neuron cell surface. ${ }^{36}$ Cells were treated with $125 \mathrm{U} / \mathrm{ml}$ collagenase and incubated for 40 min on ice with the mouse monoclonal anti-PSA N-CAM antibody diluted 1:100. They were then rinsed three times with culture medium and finally incubated with a PE-conjugated goat anti-mouse IgM (PE from Jackson ImmunoResearch) diluted at 1:80 for 30 min on ice. Cells were incubated with fluorescein-di- $\beta$, D-galactopyrannoside (FDG, Jackson ImmunoResearch) for $1 \mathrm{~min}$ at $37^{\circ} \mathrm{C}$ and stored on ice until FACS analysis. (e) Fluorescence intensity values for transfected fibroblasts and PSA N-CAM-positive cells. Note that fluorescence intensity was five times higher in neurons than in fibroblasts, reflecting differential SMN promoter activity in neurons and fibroblasts. The results are means \pm SD for at least five independent experiments. The differences between the two types of cells were significant $(P<0.005)$. 
non-neuronal cells seems to be involved in SMN promoter activity.

The key question in SMA pathology is why the deletion of the SMN1 gene decreases the amount of SMN protein in the spinal cord by a factor of 100 , and that in the fibroblasts of type I patients by a factor of $10 .^{4}$ These decreases in SMN production may be accounted for by differences in basal expression and tissue-specific regulation between the SMN1 and SMN2 promoters, in neurons, for instance. Our results demonstrate that the SMN1 and SMN2 promoters are identical and that embryonic neurons produce five times as many SMN transcripts as fibroblasts. The decrease in SMN protein levels differs by an order of magnitude in neurons and non-neuronal cells. There are two possible reasons for this: (i) a difference in cis regulatory regions at some distance from $S M N$ genes, (ii) a differential stability of the SMN2 gene product, the $\mathrm{SMN} \Delta \mathrm{Ex} 7$ protein, in neurons compared with non-neuronal cells. Interestingly, neurons transfected with SMN lacking exon-7 had significantly shorter neurites, ${ }^{13}$ suggesting that SMN protein may play a key role in neurite outgrowth, via its possible involvement in nucleocytoplasmic and dendritic transport. ${ }^{12,48}$. In vitro analysis of transfected cells in primary cultures of neurons and of fibroblasts, together with in vivo analysis of transgenic mice with SMN knockin reporter gene mice, may make it possible to test these hypotheses. Furthermore, the transfection of primary spinal cord cultures can be used to investigate further the sequences responsible for silencing in non-neuronal cells. In vivo manipulation of this mechanism could be used to increase SMN protein production in the neurons of SMA patients.

\section{Acknowledgements}

We wish to thank Drs Bénedicte Gerard and Suzie Lefebvre for providing DNA samples from patients and comments on the manuscript, Dr Judith Melki for plasmids, Dr Jorge Gallego for help with statistics, Drs Noufissa Oudhiri and Pierre Lehn for the CMVpGL2 construct, and Dr Geneviève Rougon for anti-PSA N-CAM antibodies. We thank the Institut Federatif de Recherche 02 (Faculté X. Bichat, Paris VII, France), Dr Alain Vandewalle and Françoise Cluzeaud (INSERM U478, Paris, France) for assistance with confocal microscopy. This work was supported by a grant from INSERM. BB and CM were supported by Cino del Duca Foundation and France-Telecom Foundation fellowships, respectively.

\section{References}

1 Dubowitz V: Diagnosis and classification of the neuromuscular disorders; in Dubowitz V (ed). Muscle disorders in childhood, 3rd edn. Philadelphia: W.B.Saunders; 1995, pp 2-3.

2 Lefebvre S, Burglen L, Reboullet $\mathrm{S}$ et al: Identification and characterization of a spinal muscular atrophy-determining gene (see comments). Cell 1995; 80: 155-165.

3 Lorson CL, Hahnen E, Androphy EJ, Wirth B: A single nucleotide in the SMN gene regulates splicing and is responsible for spinal muscular atrophy. Proc Natl Acad Sci USA 1999; 96: 6307-6311.
4 Coovert DD, Le TT, McAndrew PE et al: The survival motor neuron protein in spinal muscular atrophy. Hum Mol Genet 1997; 6: $1205-1214$.

5 Helmken C, Hofmann Y, Schoenen $\mathrm{F}$ et al: Evidence for a modifying pathway in SMA discordant families: reduced SMN level decreases the amount of its interacting partners and Htra2beta1. Hum Genet 2003; 114: 11-21.

6 Frugier T, Nicole S, Cifuentes-Diaz C, Melki J: The molecular bases of spinal muscular atrophy. Curr Opin Genet Dev 2002; 12: 294-298.

7 Meister G, Eggert C, Fischer U: SMN-mediated assembly of RNPs: a complex story. Trends Cell Biol 2002; 12: 472-478.

8 Pellizzoni L, Kataoka N, Charroux B, Dreyfuss G: A novel function for SMN, the spinal muscular atrophy disease gene product, in pre-mRNA splicing. Cell 1998; 95: 615-624.

9 Burlet P, Huber C, Bertrandy S et al: The distribution of SMN protein complex in human fetal tissues and its alteration in spinal muscular atrophy. Hum Mol Genet 1998; 7: $1927-1933$

10 Lefebvre S, Burlet P, Liu Q et al: Correlation between severity and SMN protein level in spinal muscular atrophy. Nat Genet 1997; 16: $265-269$.

11 Andreassi C, Patrizi AL, Monani UR, Burghes AH, Brahe C, Eboli ML: Expression of the survival of motor neuron (SMN) gene in primary neurons and increase in SMN levels by activation of the $\mathrm{N}$-methyl-D-aspartate glutamate receptor. Neurogenetics 2002; 4: $29-36$.

12 Fan L, Simard LR: Survival motor neuron (SMN) protein: role in neurite outgrowth and neuromuscular maturation during neuronal differentiation and development. Hum Mol Genet 2002; 11: 1605-1614.

13 Zhang HL, Pan F, Hong D, Shenoy SM, Singer RH, Bassell GJ: Active transport of the survival motor neuron protein and the role of exon-7 in cytoplasmic localization. J Neurosci 2003; 23: $6627-6637$.

14 McWhorter ML, Monani UR, Burghes AH, Beattie CE: Knockdown of the survival motor neuron (Smn) protein in zebrafish causes defects in motor axon outgrowth and pathfinding. J Cell Biol 2003; 162: 919-931.

15 Hsieh-Li HM, Chang JG, Jong YJ et al: A mouse model for spinal muscular atrophy. Nat Genet 2000; 24: 66-70.

16 Germain-Desprez D, Brun T, Rochette C, Semionov A, Rouget R, Simard LR: The SMN genes are subject to transcriptional regulation during cellular differentiation. Gene 2001; 279: $109-117$.

17 Echaniz-Laguna A, Miniou P, Bartholdi D, Melki J: The promoters of the survival motor neuron gene (SMN) and its copy (SMNc) share common regulatory elements. Am J Hum Genet 1999; 64: $1365-1370$.

18 Gerard B, Ginet N, Matthijs G et al: Genotype determination at the survival motor neuron locus in a normal population and SMA carriers using competitive PCR and primer extension. Hum Mutat 2000; 16: 253-263.

19 Schug J, Overton GC: Modeling transcription factor binding sites with Gibbs sampling and minimum description length encoding. Proc Int Conf Intell Syst Mol Biol 1997; 5: 268-271.

20 Quandt K, Frech K, Karas H, Wingender E, Werner T: MatInd and MatInspector: new fast and versatile tools for detection of consensus matches in nucleotide sequence data. Nucleic Acids Res 1995; 23: 4878-4884.

21 Wingender E, Chen X, Hehl R et al: TRANSFAC: an integrated system for gene expression regulation. Nucleic Acids Res 2000; 28: 316-319.

22 Ransom BR, Neale E, Henkart M, Bullock PN, Nelson PG: Mouse spinal cord in cell culture. I. Morphology and intrinsic neuronal electrophysiologic properties. I Neurophysiol 1977; 40: $1132-1150$

23 Sambrook J, Fritsch EF, Maniatis T: Molecular cloning: a laboratory manual. Cold Spring Harbor, USA: Cold Spring Harbor Laboratory Press; 1989. 
24 Leconte L, Santha M, Fort C, Poujeol C, Portier MM, Simonneau M: Cell type-specific expression of the mouse peripherin gene requires both upstream and intragenic sequences in transgenic mouse embryos. Brain Res Dev Brain Res 1996; 92: 1-9.

25 Nolan GP, Fiering S, Nicolas JF, Herzenberg LA: Fluorescenceactivated cell analysis and sorting of viable mammalian cells based on beta-D-galactosidase activity after transduction of Escherichia coli lacZ. Proc Natl Acad Sci USA 1988; 85: 2603-2607.

26 Scharf JM, Endrizzi MG, Wetter A et al: Identification of a candidate modifying gene for spinal muscular atrophy by comparative genomics. Nat Genet 1998; 20: 83-86.

27 Gerard B, Ginet N, Matthijs G et al: Genotype determination at the survival motor neuron locus in a normal population and SMA carriers using competitive PCR and primer extension. Hum Mutat 2000; 16: 253-263.

28 Kent WJ, Sugnet CW, Furey TS et al: The human genome browser at UCSC. Genome Res 2002; 12: 996-1006.

29 Chen ZF, Paquette AJ, Anderson DJ: NRSF/REST is required in vivo for repression of multiple neuronal target genes during embryogenesis. Nat Genet 1998; 20: 136-142.

30 Chong JA, Tapia-Ramirez J, Kim S et al: REST: a mammalian silencer protein that restricts sodium channel gene expression to neurons. Cell 1995; 80: 949-957.

31 Schoenherr CJ, Anderson DJ: The neuron-restrictive silencer factor (NRSF): a coordinate repressor of multiple neuron-specific genes. Science 1995; 267: 1360-1363.

32 Zuccato C, Tartari M, Crotti A et al: Huntingtin interacts with REST/NRSF to modulate the transcription of NRSE-controlled neuronal genes. Nat Genet 2003; 35: 76-83.

33 Kanai Y, Hirokawa N: Sorting mechanisms of tau and MAP2 in neurons: suppressed axonal transit of MAP2 and locally regulated microtubule binding. Neuron 1995; 14: 421-432.

34 Hirokawa N, Takeda S: Gene targeting studies begin to reveal the function of neurofilament proteins. J Cell Biol 1998; 143: 1-4.

35 Duprey P, Paulin D: What can be learned from intermediate filament gene regulation in the mouse embryo. Int J Dev Biol 1995; 39: 443-457.

36 Boisseau S, Nedelec J, Poirier V, Rougon G, Simonneau M: Analysis of high PSA N-CAM expression during mammalian spinal cord and peripheral nervous system development. Development 1991; 112: 69-82.
37 Schrank B, Gotz R, Gunnersen JM et al: Inactivation of the survival motor neuron gene, a candidate gene for human spinal muscular atrophy, leads to massive cell death in early mouse embryos. Proc Natl Acad Sci U S A 1997; 94: 9920-9925.

38 Viollet L, Bertrandy S, Bueno Brunialti AL et al: cDNA isolation, expression, and chromosomal localization of the mouse survival motor neuron gene (Smn). Genomics 1997; 40: 185-188.

39 Tusie-Luna MT, White PC: Gene conversions and unequal crossovers between CYP21 (steroid 21-hydroxylase gene) and CYP21P involve different mechanisms. Proc Natl Acad Sci USA 1995; 92: 10796-10800.

40 The International Polycystic Kidney Disease Consortium Polycystic kidney disease: the complete structure of the PKD1 gene and its protein. Cell 1995; 81: 289-298.

41 Peoples R, Franke Y, Wang YK et al: A physical map, including a $\mathrm{BAC} / \mathrm{PAC}$ clone contig, of the Williams-Beuren syndrome deletion region at 7q11.23. Am J Hum Genet 2000; 66: 47-68.

42 Emanuel BS, Shaikh TH: Segmental duplications: an 'expanding' role in genomic instability and disease. Nat Rev Genet 2001; 2: 791-800.

43 Benson M, Pirrotta V: The Drosophila zeste protein binds cooperatively to sites in many gene regulatory regions: implications for transvection and gene regulation. EMBO J 1988; 7: 3907-3915.

44 Okladnova O, Poleev A, Fantes J, Lee M, Plachov D, Horst J: The genomic organization of the murine $\operatorname{Pax} 8$ gene and characterization of its basal promoter. Genomics 1997; 42: $452-461$.

45 Jacob A, Budhiraja S, Reichel RR: Differential induction of HNF-3 transcription factors during neuronal differentiation. Exp Cell Res 1997; 234: 277-284.

46 Mitchell PJ, Timmons PM, Hebert JM, Rigby PW, Tjian R: Transcription factor AP-2 is expressed in neural crest cell lineages during mouse embryogenesis. Genes Dev 1991; 5: $105-119$.

47 Monani UR, McPherson JD, Burghes AH: Promoter analysis of the human centromeric and telomeric survival motor neuron genes (SMNC and SMNT). Biochim Biophys Acta 1999; 1445: 330-336.

48 Bechade C, Rostaing P, Cisterni C et al: Subcellular distribution of survival motor neuron (SMN) protein: possible involvement in nucleocytoplasmic and dendritic transport. Eur J Neurosci 1999; 11: $293-304$. 